\title{
Occurrence of Mycotoxins in Feedstuffs of Dairy Cows and Estimation of Total Dietary Intakes
}

\author{
F. Driehuis, ${ }^{* 1}$ M. C. Spanjer, $†$ J. M. Scholten, $†$ and M. C. te Giffel ${ }^{\star}$ \\ *Department of Health and Safety, NIZO Food Research, PO Box 20, NL-6710 BA Ede, the Netherlands \\ †Food and Consumer Product Safety Authority (VWA), National Reference Laboratory for Mycotoxins and Pesticides in Food, \\ Hoogte Kadijk 401, NL-1018 BK Amsterdam, the Netherlands
}

\section{ABSTRACT}

A survey was conducted to determine the occurrence of mycotoxins in feedstuffs of dairy cows in the Netherlands and to estimate total dietary intakes of these compounds. Twenty-four dairy farms were visited twice and samples taken of all diet ingredients. Feed intake data were collected by means of questionnaires. A total of 169 feed samples were collected and analyzed for 20 mycotoxins using a liquid chromatography tandem mass spectrometry multimethod. Silage and compound feed were the main diet ingredients, representing on average 67 and $23 \%$ of dry matter intake, respectively. Deoxynivalenol (DON), zearalenone, roquefortine $\mathrm{C}$, and mycophenolic acid were the mycotoxins with the highest incidence. The incidence of DON in silage, compound feed, and feed commodity samples was 38 to $54 \%$. The incidence of zearalenone in silage, compound feed, and feed commodity samples was 17 to $38 \%$. The DON and zearalenone had a low incidence in forage samples and were not detected in ensiled by-product samples. Roquefortine $\mathrm{C}$ and mycophenolic acid were only detected in silage and ensiled by-product samples (incidence 7 to $19 \%$ ). Fumonisins $\mathrm{B}_{1}$ and $\mathrm{B}_{2}$ were detected in 2 compound feed samples and one feed commodity sample. Aflatoxins $\mathrm{B}_{1}, \mathrm{~B}_{2}, \mathrm{G}_{1}$, and $\mathrm{G}_{2}$, ochratoxin A, T-2 and HT-2 toxin, 3-acetyl-DON, 15-acetyl-DON, diacetoxyscirpenol, sterigmatocystin, fusarenon-X, ergotamine, and penicillinic acid were not detected in any of the samples. Average concentrations of DON, zearalenone, roquefortine $\mathrm{C}$, and mycophenolic acid in complete diets were $273,28,114$, and $54 \mu \mathrm{g} / \mathrm{kg}$, respectively. Maximum concentrations were 969, 203, 2,211, and $1,840 \mu \mathrm{g} / \mathrm{kg}$, respectively. Calculated average daily intakes of these mycotoxins were 5.0, 0.5, 2.0, and 0.9 $\mathrm{mg}$ /animal, respectively, and maximum daily intakes 19.3, 3.5, 38.9, and $32.3 \mathrm{mg} / \mathrm{animal}$, respectively. Corn silage was the major source of all 4 of these mycotoxins

Received February 12, 2008.

Accepted July 6, 2008.

${ }^{1}$ Corresponding author: frank.driehuis@nizo.nl in the diet. Extremely high concentrations of roquefortine $\mathrm{C}$ and mycophenolic acid (up to 45 and $25 \mathrm{mg} / \mathrm{kg}$, respectively) were detected in visibly molded areas in surface layers of corn silage. These areas appeared to be the main source of roquefortine $\mathrm{C}$ and mycophenolic acid in the diet. Because carry-over of DON, zearalenone, roquefortine $\mathrm{C}$, and mycophenolic acid into milk is negligible, their occurrence in feedstuffs is not considered of significant concern with respect to the safety of dairy products for consumers. Potential implications for animal health are discussed.

Key words: mycotoxin, dairy cow, feed, total dietary intake

\section{INTRODUCTION}

Animal feed materials are frequently contaminated with mycotoxins. The major classes of mycotoxins of concern in feedstuffs include aflatoxins, deoxynivalenol (DON) and other trichothecenes, zearalenone, fumonisins, ochratoxin A, and ergot alkaloids (CAST, 2003). Of these mycotoxins, DON has the greatest prevalence in feedstuffs (between 20 and 100\%) and is found in forage feeds, in forage corn in particular, and in ingredients for concentrate feeds (Spahr et al., 1999; Whitlow and Hagler, 2005; Driehuis et al., 2008). Ensiled forages such as grass and corn silage may be contaminated with roquefortine $\mathrm{C}$ and mycophenolic acid, which are produced by the acid-tolerant mold Penicillium roqueforti. This species is able to grow at low levels of oxygen and is the most common spoilage mold in silage (Pahlow et al., 2003). Prevalences of roquefortine $\mathrm{C}$ and mycophenolic acid in silage samples of 56 and $32 \%$, respectively, have been reported in surveys in Germany (Auerbach et al., 1998; Schneweis et al., 2000).

From the perspective of dairying, mycotoxins in feedstuffs are of dual concern. First, occurrence of aflatoxin $\mathrm{B}_{1}$ in feed may jeopardize the safety of milk and milk products because of (partial) carry-over from feed to milk as aflatoxin $\mathrm{M}_{1}$ (EFSA, 2004a). Therefore, many countries have legislation and monitoring programs for 
aflatoxin $B_{1}$ in feedstuffs and aflatoxin $M_{1}$ in milk. Results of surveys of aflatoxin $\mathrm{M}_{1}$ in milk and milk products in several countries, including European Union (EU) member states, the United States, and Canada, indicate a high degree of compliance with legislation (FAO, 2001). Other commonly occurring feed-associated mycotoxins, including DON, zearalenone, fumonisins, and ochratoxin A, are not considered of practical relevance from the view of the safety of milk and dairy products for consumers due to low carry-over rates from feed to milk (EFSA, 2004b,c,d, 2005). The second concern is the detrimental effect that mycotoxins can have on animal health and productivity. The most prominent toxicological effects of the major classes of mycotoxins in cattle are known (CAST, 2003). However, little is known about possible synergistic or antagonistic effects of mycotoxins and whether frequent exposure of animals to low doses of mycotoxins leads to chronic health problems.

In this context it is important to have information about the dietary exposure of cattle to mycotoxins. Although there have been some studies reporting the incidence and concentrations of mycotoxins in different types of feedstuffs, data about the total daily dietary intake of mycotoxins by dairy cattle under practical farming conditions are not available. In this study a survey including 24 dairy farms in the Netherlands was conducted to determine the total dietary intake of 20 different mycotoxins in lactating cows that were fed a regular silage-based diet. The contribution of different feed ingredients in the diet, such as silages and concentrates, to the total intake was estimated. In addition, the distribution of roquefortine $\mathrm{C}$ and mycophenolic acid in silages was determined.

\section{MATERIALS AND METHODS}

\section{Sample Collection for Determination of Mycotoxins in Diets}

Samples of all diet components that were fed to lactating cows were collected at 24 dairy farms with highproducing dairy cows spread across the Netherlands. Each farm was visited and sampled twice by trained staff of the Laboratory for Soil and Crop Testing (Blgg), Oosterbeek, the Netherlands. The first series of samples was collected between February and April 2005, the second series in November and December 2005. Five classes of feedstuffs were collected: silage, forage products, compound feed, feed commodities, and ensiled by-products. Numbers of feedstuff samples collected are listed in Table 1. The sample size was 200 to $500 \mathrm{~g}$. Samples of compound feed were taken directly from the feeding trough in the barn where the animals
Table 1. Type and numbers of feedstuff samples collected

\begin{tabular}{lccc}
\hline & \multicolumn{3}{c}{ Number of samples } \\
\cline { 2 - 4 } Feed & 1st series & 2nd series & Total \\
\hline Silage & 24 & 23 & 47 \\
Compound feed & 35 & 37 & 72 \\
Ensiled by-products & 17 & 12 & 29 \\
Pressed sugar beet pulp & 9 & 3 & 12 \\
Brewer's spent grains & 7 & 8 & 15 \\
Potato pulp & 1 & 1 & 2 \\
Feed commodities & 1 & 7 & 8 \\
Rapeseed/soy meal & 0 & 4 & 4 \\
Corn gluten meal & 1 & 1 & 2 \\
Cereal grains & 0 & 2 & 2 \\
Forage products & 3 & 10 & 13 \\
Fresh grass & 0 & 5 & 5 \\
Dried grass & 0 & 2 & 2 \\
Grass hay & 3 & 3 & 6 \\
\hline
\end{tabular}

${ }^{1}$ Mixture of grass and corn silage.

${ }^{2}$ Hay from grass seed production.

were housed. Feed commodity samples were taken from the bulk storage container. Silage samples were composite samples of 10 samples of approximately 50 $\mathrm{g}$ of the silage that was offered to the dairy cows in the barn, taken at different positions. Generally, silage offered to cows in the barn consisted of a mixture of grass and corn silage, except in 4 cases in which it consisted of grass silage only, and one case in which it consisted of corn silage only. Samples of ensiled byproducts were composite samples of 10 samples of approximately $50 \mathrm{~g}$ taken at different positions of the silo front face. Samples of forage products were composite samples of 10 samples of approximately $50 \mathrm{~g}$ taken at different positions of the pasture (fresh grass) or the storage facility (dried grass and hay). Data concerning diet composition and the amounts of each feedstuff fed daily to lactating cows were collected using a questionnaire filled out by the farm manager at each visit.

\section{Sample Collection for Determination of Mycotoxins in Grass and Corn Silage}

Sixteen dairy farms from the group of 24 farms used in the dietary intake survey were visited in April 2005 (8 farms) and December 2005 (8 farms). Samples were collected from the grass and corn silages that were being used in the cattle ration at the time of the visit and from the mixture of grass and corn silage offered to the animals in the barn. The plastic sheets covering the silages were removed from the front side to allow daily removal of silage for feeding. Samples were taken from the surface layer as well as from the core area of the front face of the silages. The front face was divided into 2 sections: the core, defined as the area of at least $0.3 \mathrm{~m}$ distance from the surface, and the surface layer, 
defined as the outermost $0.2 \mathrm{~m}$ of the silage. From both sections samples of approximately $50 \mathrm{~g}$ were taken by hand at 10 different positions and mixed to provide composite samples. Samples of areas with visible molds (molded spots) in corn silage were taken by sampling a maximum of 10 molded spots and mixing them to provide a composite sample. Molded spots and the $0.15 \mathrm{~m}$ surrounding these spots were excluded from the core and surface layer samples. In addition, 10 samples of approximately $50 \mathrm{~g}$ of the mixture of grass and corn silage offered to dairy cows in the barn were taken at different positions and mixed to provide a composite sample.

\section{Analytical Methods}

On receipt, samples were air-dried at $70^{\circ} \mathrm{C}$ for $24 \mathrm{~h}$ in an oven, ground to pass a $1-\mathrm{mm}$ screen, and homogenized. This procedure provided a fine, homogeneous powder, which was used for analysis of mycotoxins and DM, as described previously (Driehuis et al., 2008). A liquid chromatography/mass spectrometry (LC-MS/ MS) method was used to analyze 20 mycotoxins in a single analysis run (Spanjer et al., 2008). Dried and ground sample $(5 \mathrm{~g})$ was mixed with $100 \mathrm{~mL}$ of $80 \%$ (vol/vol) acetonitrile in water and shaken for $2 \mathrm{~h}$. The mixture was diluted 4 times with water and filtered through a $0.45-\mu \mathrm{m}$ pore size nitrocellulose membrane filter. The LC-MS sytem consisted of a Waters Alliance 2695 HPLC system (Waters, Milford, MA), coupled to a Quattro Ultima triple quadrupole mass spectrometer (Waters-Micromass, Manchester, UK) equipped with a pneumatically assisted electrospray interface. Mycotoxins were separated on a reversed-phase column (Alltima C18, $150 \mathrm{~mm} \times 3.2 \mathrm{~mm}$ i.d., 5 - $\mu \mathrm{m}$ particle size, Alltech, Breda, the Netherlands) at a column temperature of $30^{\circ} \mathrm{C}$. The mobile phase was composed of a gradient of $0.1 \%$ formic acid in water and $0.1 \%$ formic acid in acetonitrile (gradient from 90/10 to 10/90) and was eluted at a flow rate of $0.3 \mathrm{~mL} / \mathrm{min}$. The mass spectrometer operated in the positive mode under the following conditions: capillary voltage, $2.5 \mathrm{kV}$; desolvation temperature, $450^{\circ} \mathrm{C}$; desolvation gas flow (nitrogen), 600 $\mathrm{L} / \mathrm{h}$; cone voltage, variable; cone gas flow (nitrogen), $100 \mathrm{~L} / \mathrm{h}$; nebulizer gas (nitrogen), fully open; collision gas flow (argon), 0.8 bar on pressure regulator. For each mycotoxin the parent and 2 daughter ions were detected. Sample volumes of $20 \mu \mathrm{L}$ were injected. Data were processed with Masslynx and Quanlynx software. Standard solutions of mycotoxins (Sigma-Aldrich Chemie B.V., Zwijndrecht, the Netherlands) were used to prepare calibration curves in solvent and in sample extracts to determine ion suppression effects, recoveries, and limits of quantification (LOQ; set at a signal
Table 2. Mycotoxins analyzed and their limits of quantification (LOQ)

\begin{tabular}{lc}
\hline Mycotoxin & LOQ $(\mu \mathrm{g} / \mathrm{kg})$ \\
\hline Aflatoxin $\mathrm{B}_{1}$ & 8 \\
Aflatoxin $_{2}$ & 8 \\
Aflatoxin $_{1}$ & 15 \\
Aflatoxin $\mathrm{G}_{2}$ & 15 \\
Deoxynivalenol (DON) & 125 \\
3-Acetyl-DON & 250 \\
15-Acetyl-DON & 250 \\
Diacetoxyscirpenol & 100 \\
Ergotamine & 50 \\
Fumonisin $\mathrm{B}_{1}$ & 100 \\
Fumonisin $\mathrm{B}_{2}$ & 100 \\
Fusarenon-X & 250 \\
Ochratoxin A & 8 \\
Mycophenolic acid & 25 \\
Penicillinic acid & 100 \\
Roquefortine C & 50 \\
Sterigmatocystin & 50 \\
T-2 toxin & 100 \\
HT-2 toxin & 250 \\
Zearalenone & 25 \\
\hline
\end{tabular}

to noise ratio of 6:1), as described previously (Spanjer et al., 2008). For each mycotoxin the LOQ was assessed based on 6 replicate determinations at 3 concentration levels. The mycotoxins determined and their LOQ are listed in Table 2. To determine recoveries, sample extracts were spiked with mycotoxins at the LOQ, 5 times the LOQ and 10 times the LOQ. Zearalenone was spiked at 200, 1,000, and 2,000 $\mathrm{kg} / \mathrm{kg}$. Overall recoveries of mycotoxins in 3 feed matrices varied from 73 to $111 \%$. Results were corrected for recovery. To determine repeatability, a silage sample contaminated with DON, roquefortine $\mathrm{C}$, and mycophenolic acid was added as a control sample to 4 analysis series during a period of 5 mo. The following average concentrations and relative standard deviations (RSD) were obtained. DON: 1,810 $\mu \mathrm{g} / \mathrm{kg}, \mathrm{RSD} 13 \%$; roquefortine C: $160 \mu \mathrm{g} / \mathrm{kg}$, RSD 25\%; mycophenolic acid: $239 \mu \mathrm{g} / \mathrm{kg}$, RSD 18\%.

\section{Statistical Analysis}

To calculate averages and SEM values, values below the detection level were assigned a value corresponding to half the detection level. Student's $t$-test was used to detect significant differences among samples.

\section{RESULTS}

\section{Representativeness of the Survey}

The selection of dairy farms and the sample collection procedures were designed to obtain sample sets that were representative of diets fed to high-producing dairy cows in the Netherlands. The 24 farms included 
Table 3. Incidence and concentrations of deoxynivalenol (DON) and zearalenone in different diet ingredients

\begin{tabular}{|c|c|c|c|c|c|c|c|}
\hline \multirow[b]{2}{*}{ Ingredient } & \multirow[b]{2}{*}{ Samples, $\mathrm{n}$} & \multicolumn{3}{|c|}{$\mathrm{DON}$} & \multicolumn{3}{|c|}{ Zearalenone } \\
\hline & & $\begin{array}{c}\text { Positive } \\
\text { samples }^{1}(\%)\end{array}$ & Average $^{2}$ & Maximum & $\begin{array}{c}\text { Positive } \\
\text { samples (\%) }\end{array}$ & Average & Maximum \\
\hline Silage & 47 & $25(53)$ & $550(53)$ & 1,250 & $8(17)$ & $125(33)$ & 273 \\
\hline Compound feed & 72 & $39(54)$ & $433(66)$ & 2,408 & $20(28)$ & $80(17)$ & 363 \\
\hline Ensiled by-products & 29 & $0(0)$ & - & - & $0(0)$ & - & - \\
\hline
\end{tabular}

${ }^{1}$ Number of silages with a mycotoxin concentration greater than the limit of quantification.

${ }^{2}$ Average concentration and SEM (value between parentheses) of positive samples.

in the survey were located in different regions of the Netherlands. The average herd size of these farms was 69 dairy cows, which was only slightly greater than the average herd size of dairy farms in the Netherlands in 2005 of 61 dairy cows (LEI, 2006). Silage and compound feed were the main feedstuff classes in the diets at the 24 farms, representing, on average, 69 and $23 \%$ of the total DMI of the animals, respectively. This was in agreement with the typical ratio of roughage to compound feed of $3: 1$ in diets of high-producing dairy cows in the Netherlands during the winter season when the animals are housed (Van Duinkerken et al., 2007). The silage fraction in the diet generally consisted of a mixture of grass silage and whole crop corn silage. The average DM concentration and $\mathrm{pH}$ of the silages analyzed in the survey and silages analyzed as part of a feed analysis service to farmers by the Laboratory for Soil and Crop Testing (Blgg), Oosterbeek, representing approximately $75 \%$ of the total number of silages produced in the Netherlands, were similar (data not shown). These observations confirm the representativeness of the survey.

\section{Mycotoxins in Different Feedstuffs}

Deoxynivalenol was the most frequently detected mycotoxin in this survey. The incidence of DON was particularly high in compound feed and silage samples. It was detected above the LOQ of $125 \mathrm{\mu g} / \mathrm{kg}$ in 54 and $53 \%$ of these feed classes, respectively (Table 3). The average concentration of DON in DON-positive samples of compound feed and silage was 433 and $550 \mathrm{\mu g} /$ $\mathrm{kg}$, respectively. Deoxynivalenol was detected in only 5 samples of other feed classes: 2 corn gluten samples, 1 barley sample, and 2 grass hay samples. It was not detected in any of the ensiled by-product samples.

The concentration of DON was $<8,000 \mu \mathrm{g} / \mathrm{kg}$ in all samples. This concentration is the guidance value for cereals and cereal products, including products derived from corn forage, recommended in EC legislation (Eu- ropean Commission, 2006). A maximum concentration of $2,408 \mu \mathrm{g} / \mathrm{kg}$ of DON was detected in a sample of compound feed. No significant differences were found between the first and second series of samples regarding the incidence of DON in compound feed and the average DON concentration in DON-positive compound feed samples. Also, the incidence of DON in silage samples did not differ between the first and second series. However, the first series of silage samples had a significantly greater $(P<0.01)$ average DON concentration than the second series (736 and $405 \mu \mathrm{g} /$ $\mathrm{kg}$, respectively).

Zearalenone was detected in $28 \%$ of compound feed samples and $17 \%$ of silage samples (Table 3). Average concentrations of zearalenone in these feed classes were 125 and $80 \mu \mathrm{g} / \mathrm{kg}$, respectively. Zearalenone was detected in 4 samples of other feed classes: a corn gluten sample, a barley sample, a grass hay sample, and a sample of artificially dried grass.

The zearalenone concentration was $<2,000 \mu \mathrm{g} / \mathrm{kg}$ in all samples, the guidance value for cereals and cereal products, including products derived from corn forage, recommended in EC legislation (European Commission, 2006). A maximum concentration of $363 \mu \mathrm{g} / \mathrm{kg}$ of zearalenone was detected in a sample of compound feed.

The incidence of zearalenone in silage and compound feed and the average zearalenone concentration in zearalenone-positive samples were significantly higher $(P<0.05)$ in the first series than in the second series.

Co-occurrence of DON and zearalenone was frequently observed. In all zearalenone-positive silage samples and $75 \%$ of zearalenone-positive compound feed samples, DON was also detected.

Roquefortine $\mathrm{C}$ and mycophenolic acid were detected exclusively in feeds preserved by ensiling. Roquefortine $\mathrm{C}$ was detected in $19 \%$ of silage samples and $7 \%$ of samples of ensiled by-products. Mycophenolic acid was detected in 13 and 10\% of samples of these feed classes, respectively (Table 4). Roquefortine $\mathrm{C}$ and my- 
Table 4. Incidence and concentrations of roquefortine $\mathrm{C}$ and mycophenolic acid in silage and ensiled by-products

\begin{tabular}{|c|c|c|c|c|c|c|c|}
\hline \multirow[b]{2}{*}{ Feed class } & \multirow[b]{2}{*}{ Samples, $\mathrm{n}$} & \multicolumn{3}{|c|}{ Roquefortine $\mathrm{C}$} & \multicolumn{3}{|c|}{ Mycophenolic acid } \\
\hline & & $\begin{array}{c}\text { Positive } \\
\text { samples }^{1}(\%)\end{array}$ & Average $^{2}$ & Maximum & $\begin{array}{c}\text { Positive } \\
\text { samples (\%) }\end{array}$ & Average & Maximum \\
\hline Silage & 47 & $9(19)$ & 778 (349) & 3,160 & $6(13)$ & $524(422)$ & 2,630 \\
\hline Ensiled by-products & 29 & $2(7)$ & $123(48)$ & 170 & $3(10)$ & $66(12)$ & 83 \\
\hline
\end{tabular}

${ }^{1}$ Number of silages with a mycotoxin concentration greater than the limit of quantification.

${ }^{2}$ Average concentration and SEM (value between parentheses) of positive samples.

cophenolic acid were frequently co-occurring: in $56 \%$ of mycophenolic acid-positive samples roquefortine $\mathrm{C}$ was also detected. Maximum concentrations of roquefortine $\mathrm{C}$ and mycophenolic acid were 3,160 and $2,630 \mu \mathrm{g} / \mathrm{kg}$, respectively, and were detected in the same silage sample.

Fumonisins $\mathrm{B}_{1}$ and $\mathrm{B}_{2}$ were detected in only 2 samples: a compound feed sample (807 and $282 \mathrm{\mu g} /$ $\mathrm{kg}$ of fumonisin $\mathrm{B}_{1}$ and $\mathrm{B}_{2}$, respectively) and a corn gluten feed sample $(1,080$ and $530 \mu \mathrm{g} / \mathrm{kg}$, respectively). Both samples did not exceed a fumonisin $\mathrm{B}_{1}+$ $\mathrm{B}_{2}$ concentration of $50,000 \mu \mathrm{g} / \mathrm{kg}$, the guidance value for complementary and complete feedstuffs for adult ruminants recommended in EC legislation (European Commission, 2006). Remarkably, the compound feed sample contaminated with fumonisins $B_{1}$ and $B_{2}$ was the sample that contained the maximum concentration of DON.

Aflatoxins $\mathrm{B}_{1}, \mathrm{~B}_{2}, \mathrm{G}_{1}$, and $\mathrm{G}_{2}$, ochratoxin $\mathrm{A}$, T-2 and HT-2 toxin, 3-acetyl-DON, 15-acetyl-DON, diacetoxyscirpenol, sterigmatocystin, fusarenon-X, ergotamine, and penicillinic acid were not detected in any of the samples.

\section{Total Daily Intake of Mycotoxins}

The estimated daily dietary uptake of mycotoxins by dairy cattle was based on mycotoxin concentrations in individual feedstuffs and diet composition and feed intake data supplied by the farm managers. The average total daily feed intake of dairy cows was $18.7 \mathrm{~kg}$ of DM per animal (Table 5). Silage and compound feed were the main ingredients of the diets (average daily intake of 12.6 and $4.3 \mathrm{~kg}$ of DM per animal, respectively). Generally, the silage fed to cows was a mixture of grass silage and whole crop corn silage. On a few occasions it consisted of only one of these silage types. The ratio of grass and corn silage at farms feeding a mixture of these feeds was on average 3:2. Ensiled by-products, feed commodities, and forage products were included in 52,19 , and $25 \%$ of the diets, respectively. In diets containing one or more of these ingredients each ingredient represented approximately $10 \%$ of total DM uptake.

Deoxynivalenolwas detected in one or more diet ingredients in 39 out of $48(81 \%)$ diets (Table 6). The average concentration of DON in DON-positive diets was $320 \mu \mathrm{g} / \mathrm{kg}$ of DM. A maximum DON concentration of $969 \mu \mathrm{g} / \mathrm{kg}$ of DM was detected, which is less than one-fifth of the guidance value for DON in complete feedstuffs for dairy cattle of $5,000 \mu \mathrm{g} / \mathrm{kg}$, recommended in EC legislation (European Commission, 2006). For cows that were fed a DON-positive diet, the average daily intake of DON was $5.9 \mathrm{mg}$ per animal. If diets in which none of the ingredients contained DON above the LOQ were included in the calculations, the estimated

Table 5. Daily intake of total diet and different diet ingredients by dairy cattle

\begin{tabular}{|c|c|c|c|c|}
\hline \multirow[b]{3}{*}{ Ingredient } & \multirow[b]{3}{*}{$\begin{array}{c}\text { Diets with } \\
\text { ingredient, }{ }^{1} \mathrm{n}\end{array}$} & \multicolumn{3}{|c|}{ Daily intake (kg of DM/animal) } \\
\hline & & \multicolumn{2}{|c|}{ Average } & \multirow[b]{2}{*}{ Maximum } \\
\hline & & All diets & $\begin{array}{l}\text { Diets with } \\
\text { ingredient }\end{array}$ & \\
\hline Silage & 47 & $12.6(0.3)^{2}$ & $12.9(0.2)$ & 16.8 \\
\hline Compound feed & 47 & $4.3(0.2)$ & $4.4(0.2)$ & 7.0 \\
\hline Ensiled by-products & 25 & $0.9(0.2)$ & $1.7(0.2)$ & 3.5 \\
\hline Feed commodities & 9 & $0.3(0.4)$ & $1.8(0.1)$ & 4.4 \\
\hline Forage products & 12 & $0.5(1.0)$ & $2.1(0.3)$ & 12.3 \\
\hline Total diet & & $18.7(1.3)$ & & 21.8 \\
\hline
\end{tabular}


Table 6. Concentration in diet and daily intake by dairy cattle of deoxynivalenol (DON), zearalenone, roquefortine C, and mycophenolic acid

\begin{tabular}{|c|c|c|c|c|c|c|c|}
\hline \multirow[b]{2}{*}{ Mycotoxin } & \multirow{2}{*}{$\begin{array}{c}\text { Positive } \\
\text { diets, }{ }^{1} \mathrm{n}(\%)\end{array}$} & \multicolumn{3}{|c|}{ Concentration in $\operatorname{diet}(\mu \mathrm{g} / \mathrm{kg})$} & \multicolumn{3}{|c|}{ Total daily intake (mg/animal) } \\
\hline & & Positive diets & All $\operatorname{diets}^{2}$ & Maximum & Positive diets & All $\operatorname{diets}^{2}$ & Maximum \\
\hline $\mathrm{DON}$ & $39(81)$ & $320(40)^{3}$ & $273(36)$ & 969 & $5.9(0.7)$ & $5.0(0.7)$ & 19.3 \\
\hline Zearalenone & $22(46)$ & $44(12)$ & $28(6)$ & 203 & $0.8(0.2)$ & $0.5(0.1)$ & 3.5 \\
\hline Roquefortine C & $11(23)$ & $430(202)$ & $114(51)$ & 2,211 & $7.9(3.6)$ & $2.0(0.9)$ & 38.9 \\
\hline
\end{tabular}

${ }^{1}$ Diets with mycotoxin detected in one or more diet ingredients out of a total of 48 diets analyzed.

${ }^{2}$ Averages were based on the assumption that in negative diets the DON and zearalenone concentrations in all diet ingredients and roquefortine $\mathrm{C}$ and mycophenolic acid concentrations in silage and ensiled by-products were $50 \%$ of the limit of quantification.

${ }^{3} \mathrm{SEM}$ between parentheses.

average daily intake was $5.0 \mathrm{mg}$ of DON per animal. The maximum daily intake was $19.3 \mathrm{mg}$ of DON per animal.

Zearalenone was detected in 22 (46\%) diets (Table 6). The average and maximum zearalenone concentration in zearalenone-positive diets were 44 and $203 \mu \mathrm{g} /$ $\mathrm{kg}$ of DM, respectively. The maximum concentration was about 2.5-fold lower than the guidance value for zearalenone in complete feedstuffs for dairy cattle of $500 \mathrm{\mu g} / \mathrm{kg}$, recommended in EC legislation (European Commission, 2006). For cows that were fed a zearalenone-positive diet, the average daily intake of zearalenone was $0.8 \mathrm{mg}$ per animal. If diets in which none of the ingredients contained zearalenone above the LOQ were included in the calculations, the estimated average daily intake was $0.5 \mathrm{mg}$ per animal. The maximum daily intake was $3.5 \mathrm{mg}$ of zearalenone per animal.

Forty-four percent of the diets contained DON and zearalenone. In $95 \%$ of the zearalenone-positive diets, DON was also detected. In $54 \%$ of the DON-positive diets, zearalenone was also detected. Analysis of the data showed that diets high in DON were often also high in zearalenone (and vice versa). This was for example illustrated by the finding that the group of 5 diets with the greatest DON concentration included 3 diets that belonged to the group of 5 diets with the greatest zearalenone concentration.

On average, the contribution of silage to the total dietary intake of DON and zearalenone was higher than that of compound feed. The average dietary intakes of DON and zearalenone via silage were 3.5 and 2.9 times, respectively, greater than via compound feed.

Roquefortine $\mathrm{C}$ and mycophenolic acid were detected in $11(23 \%)$ and $8(17 \%)$ diets, respectively (Table 6). Thirteen diets (27\%) contained one of these mycotoxins and 6 diets (13\%) contained both. For cows that were fed a diet containing roquefortine $\mathrm{C}$ or mycophenolic acid, the average daily intake of these mycotoxins was
7.9 and $4.8 \mathrm{mg}$ per animal, respectively. These values were influenced to a great extent by one diet that contained the highest concentrations of roquefortine $\mathrm{C}$ and mycophenolic acid detected in this study. If this diet was excluded from the calculations the average daily intakes reduced to 4.8 (SEM 2.1) and 0.9 (SEM 0.3) $\mathrm{mg}$ per animal, respectively.

In only 6 diets $(13 \%$; 5 in the first sampling series and 1 in the second series) were none of the analyzed mycotoxins detected.

\section{Mycotoxins in Grass and Whole-Crop Corn Silage}

Silage samples analyzed in the dietary intake study consisted of a mixture of grass silage and whole-crop corn silage. To identify which silage type was the main source of DON, zearalenone, roquefortine $\mathrm{C}$, and mycophenolic acid, samples of grass silage and corn silage that were used in feeding were collected at 16 dairy farms. Silage samples were taken from the core, the surface layer and from surface areas with visible molds (molded spots). In addition, samples of the silage mixture that was fed to cows were collected. The results of the mycotoxin analyses indicated that corn silage was the main source of all 4 mycotoxins (Table 7). Grass silage was a minor source of zearalenone, roquefortine $\mathrm{C}$, and mycophenolic acid but not a source of DON. Concentrations of DON and zearalenone in the core and surface layer of corn silage were identical. In contrast, concentrations of roquefortine $\mathrm{C}$ and mycophenolic acid were greater in the surface layer than in the core. Extremely high concentrations of roquefortine $\mathrm{C}$ and mycophenolic acid were detected in molded spot samples from corn silage. The concentration of roquefortine $\mathrm{C}$ in these samples varied between 13 and $45 \mathrm{mg} / \mathrm{kg}$. The concentration of mycophenolic acid, which co-occurred with roquefortine $\mathrm{C}$ in 5 out of 7 samples, varied between 0.4 and $25.0 \mathrm{mg} / \mathrm{kg}$. The 


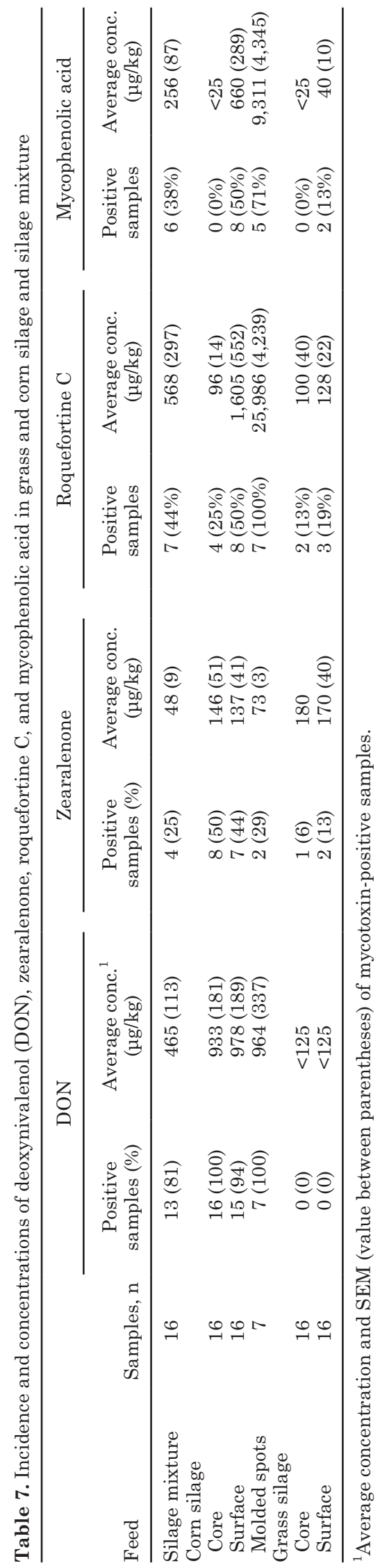

results indicate that the surface layer of corn silage, in particular areas with molded spots, is the main source of roquefortine $\mathrm{C}$ and mycophenolic acid in the diet of dairy cows.

\section{DISCUSSION}

This is the first report in which the dietary exposure of cattle to a series of mycotoxins has been quantified under practical farming conditions. The DON and zearalenone were identified as the mycotoxins with the greatest incidence in the diet (81 and 46\%, respectively), followed by the silage-associated mycotoxins roquefortine $\mathrm{C}$ and mycophenolic acid (23 and 17\%, respectively). Fumonisins $\mathrm{B}_{1}$ and $\mathrm{B}_{2}$ were detected in low concentrations in only 2 out of 48 diets (4\%). The other 15 mycotoxins analyzed in this study were not detected. In particular the low incidence of aflatoxin $\mathrm{B}_{1}$, fumonisins, and ochratoxin $\mathrm{A}$ is a notable result of this study. These mycotoxins are reported to occur relatively frequently in ingredients of compound feed as well as in corn and by-products of corn processing (Scudamore et al., 1997; Spahr et al., 1999). The results of this study indicate, first, that the occurrence of these mycotoxins in feedstuffs imported into the Netherlands appears to be adequately controlled by compound feed manufacturers. Second, they indicate that the contamination levels of aflatoxin $\mathrm{B}_{1}$, fumonisins, and ochratoxin A in forage corn harvested in the Netherlands are low. This latter result confirms results of an earlier survey of mycotoxin contamination of forage corn in the Netherlands. In that survey, which was conducted between 2002 and 2004, fumonisin $\mathrm{B}_{1}$ was detected in only 2 out of 140 corn silage samples $(1.4 \%)$ and aflatoxin $\mathrm{B}_{1}$ and ochratoxin $\mathrm{A}$ were detected in none of the samples (Driehuis et al., 2008). For aflatoxin $\mathrm{B}_{1}$ the results were not unexpected because aflatoxin contamination of corn is usually associated with geographical regions with a tropical or subtropical climate. Fumonisins and ochratoxin A, on the other hand, are frequent contaminants of corn grown in temperate regions, including north-west Europe. For instance, fumonisin $\mathrm{B}_{1}$ was detected above $100 \mathrm{\mu g} / \mathrm{kg}$ in $92 \%$ of corn samples (kernels) grown in France (De Nijs et al., 1998) and ochratoxin A was detected above $1 \mathrm{\mu g} / \mathrm{kg}$ in $4 \%$ of unprocessed cereal samples grown in EU member states (EFSA, 2004d). The low incidence of ochratoxin A and fumonisin contamination of forage corn detected in the present study and the earlier survey between 2002 and 2004, years with considerable variation in weather conditions during the corn growing season (Driehuis et al., 2008), indicates that the environmental conditions of growth of this crop in the Netherlands are apparently not favorable for infection 
by the mold species associated with production of these mycotoxins.

The 20 mycotoxins analyzed in this study belong to the major mycotoxins of concern in feedstuffs (CAST, 2003; Pahlow et al., 2003). Conclusions of this study regarding incidence of mycotoxins in feed and possible animal health implications (discussed below) are limited to these 20 mycotoxins. The possible occurrence of other mycotoxins in feedstuffs for dairy cattle, for instance fumiclavines formed by Aspergillus flavus or PR toxin formed by Penicillium species, requires more research.

\section{DON and Zearalenone}

The results of this study show that the incidence of the Fusarium mycotoxins DON and zearalenone in the diet of dairy cattle in the Netherlands was high: DON was detected in $81 \%$ of the diets and zearalenone in $46 \%$ of the diets. The incidence of DON in compound feed and silage was comparable. The incidence of zearalenone was higher in compound feed than in silage. However, quantitatively, silage was a more important source of DON and zearalenone than compound feed. The average intake of these mycotoxins via silage was approximately 3 times higher than intake via compound feed. Analysis of grass and corn silages at farms indicated that corn silage was by far the main source of DON and zearalenone in the silage mixture that was fed to cows. This result confirms results of a survey between 2002 and 2004 of mycotoxin contamination of silages in the Netherlands (Driehuis et al., 2008). In that survey DON and zearalenone were detected in 72 and $49 \%$, respectively, of corn silages and in only 0 and $6 \%$, respectively, of grass silages. The average DON and zearalenone concentrations in corn silage core samples detected in this survey (933 and $146 \mu \mathrm{g} / \mathrm{kg}$, respectively; Table 7) are comparable with those detected in the survey between 2002 and 2004 (1,004 and $174 \mathrm{\mu g} /$ kg, respectively; Driehuis et al., 2008). High incidences of DON and zearalenone in corn silage have also been reported to occur in Germany, Austria, and North Carolina in the United States (Reutter, 1999; Hochsteiner and Schuh, 2001; Whitlow and Hagler, 2005). The results of the present study were also in line with the results of survey conducted in 1984 and 1985 on the occurrence of Fusarium mycotoxins in cereal crops harvested in the Netherlands (Tanaka et al., 1990). In that study DON and zearalenone were detected in 90 and $62 \%$, respectively, of samples of wheat, barley, oats, rye, and corn.

Average DON and zearalenone concentrations were lower in compound feed samples than in silage samples (Table 3). The sources of DON and zearalenone in compound feed samples have not been identified in this study. The most likely sources are wheat, barley, and corn and by-products of the milling or processing of these crops (e.g., corn gluten and wheat bran). These feed ingredients, which are common ingredients of compound feed for cattle, are frequently contaminated by DON and zearalenone (Scudamore et al., 1997; Spahr et al., 1999). For example, a study in the United Kingdom showed that $95 \%$ of corn gluten samples used in animal feed were contaminated by DON in concentrations between 100 and $5,000 \mu \mathrm{g} / \mathrm{kg}$, and $20 \%$ of these samples were contaminated by zearalenone in concentrations between 50 and $480 \mu \mathrm{g} / \mathrm{kg}$ (Scudamore et al., 1998).

The average daily intakes of DON and zearalenone of dairy cows in our study were 5.0 and $0.5 \mathrm{mg}$ per cow, respectively. Assuming an average BW of high yielding dairy cows of $600 \mathrm{~kg}$, these values correspond to intakes of 8.4 and $0.84 \mathrm{\mu g} / \mathrm{kg}$ of BW, respectively. These are the first reported dietary mycotoxin intake values for cattle. To date, no dietary mycotoxin intake values are available for other livestock animals. Estimates of human dietary intake of DON and zearalenone in European countries ranged from 0.142 to 0.461 and 0.004 to $0.029 \mathrm{\mu g} / \mathrm{kg}$ of BW, respectively (Gareis et al., 2003).

Due to their very low carry-over rate from feed to milk, DON and zearalenone are not of significant concern with respect to the safety of dairy products for consumers (EFSA, 2004b,c). Deoxynivalenoland zearalenone are of concern to the dairy sector primarily because of their potential adverse effects on cattle health. However, limited data are available on adverse health effects of mycotoxins on dairy cattle. Recent risk assessments of DON and zearalenone in animal feed conducted by the European Food Safety Authority (EFSA) concluded that the available data do not allow the establishment of maximum tolerance levels and more dose-effect studies are needed (EFSA 2004b,c). In addition, it was concluded that more data on concentrations of DON and zearalenone in the different types of feed consumed by cattle are needed to allow reliable quantitative exposure assessments. The results presented in this study contribute to this latter need. In an increasing number of countries, governments and feed manufacturers have monitoring and control programs for DON and zearalenone in animal feed in place. These programs generally focus on feed commodities and compound feed. On-farm-produced feeds, such as silages and fresh roughages, are generally not included, or to a minimal extent. This study showed that in the diet of Dutch dairy cattle, corn silage is the major source of DON and zearalenone. It is therefore 
recommended to include corn silage in monitoring and control programs.

Based on the risk assessments by EFSA, maximum concentrations (named guidance values) for several mycotoxins in animal feed were recommended by the Commission of the European Communities (European Commission, 2006). Guidance values for DON and zearalenone in complementary and complete feedstuffs are 5,000 and $500 \mathrm{\mu g} / \mathrm{kg}$, respectively. None of the feeds and complete diets analyzed in this study contained mycotoxin concentrations that exceeded these guidance values (Table 6). Average and maximum concentration of DON in complete diets (273 and 969 $\mu \mathrm{g} / \mathrm{kg}$, respectively; Table 6) were 18.3 and 5.2 times, respectively, less than the EC guidance value. Average and maximum concentration of zearalenone in complete diets (28 and $203 \mu \mathrm{g} / \mathrm{kg}$, respectively) were 17.9 and 2.5 times, respectively, less than the EC guidance value. Therefore, no acute effects on animal health are expected. A limitation of this study was that no data concerning possible health effects were collected for the animals involved.

\section{Roquefortine C and Mycophenolic Acid}

The silage-associated mycotoxins roquefortine $\mathrm{C}$ and mycophenolic acid were detected in 13 to $19 \%$ of silage samples and 7 to $10 \%$ of samples of ensiled by-products in the first part of this study (Table 4). The more detailed analysis of grass and corn silages in the second part of the study showed that roquefortine $\mathrm{C}$ and mycophenolic acid occurred in 50\% of the corn silages in 13 to $19 \%$ of the grass silages (Table 7 ). The greatest incidences and concentrations were detected in the surface layers and visibly molded material. These results are in agreement with earlier studies showing similar high incidences of roquefortine $\mathrm{C}$ and mycophenolic acid in grass and corn silage, in particular in visibly molded areas (Auerbach et al., 1998; Schneweis et al., 2000). In contrast, much lower incidences were detected in a survey comprising 290 corn, grass, and wheat silages produced in the Netherlands between 2002 and 2004 (Driehuis et al., 2008). In that study, roquefortine C was detected in only one grass silage $(0.8 \%)$ and none of the corn and wheat silages, and mycophenolic acid was detected neither in grass nor in corn and wheat silages. These contrasting results can probably be explained by a difference in silage use at the time of sampling. In the study with the low incidence of roquefortine $\mathrm{C}$ and mycophenolic acid, samples were taken from completely sealed silages that were not yet in use for feeding purposes (Driehuis et al., 2008). However, in the studies with the high incidence of roquefortine $\mathrm{C}$ and mycophenolic acid, including the study reported in this paper, samples were taken from silages that were in use for feeding and from which the seal was partly removed. These silages were inevitably exposed to air during the feeding period. Air has a detrimental effect on silage quality because it enables growth of acid-tolerant aerobic microorganisms, including yeasts and molds (Pahlow et al., 2003). Penicillium roqueforti is usually the predominant mold species in silage because it is both acid tolerant and able to grow at low oxygen levels. To control growth of $P$. roquefort $i$ and production of roquefortine $\mathrm{C}$ and mycophenolic acid in silage, it is important to minimize exposure to oxygen and penetration of oxygen. Adequate silo sealing, a high silage density, and a high feed removal rate after silo opening are the most important measures in silage making practice to achieve this (Pahlow et al., 2003). In addition, the detrimental effects of oxygen in silage can be limited by the addition of an inhibitor of fungal growth, for instance bacterial cultures containing Lactobacillus buchneri (Driehuis et al., 2001).

Little information is available about the toxicological effects of roquefortine $\mathrm{C}$ and mycophenolic acid. The acute toxicity of these mycotoxins is low based on evaluations of their effects in mice and rats (Arnold et al., 1978; Cole and Cox, 1981). Few studies on the effects of roquefortine $\mathrm{C}$ and mycophenolic acid in ruminants have been reported. Häggblom (1990) established a relationship between disease symptoms in a herd of dairy cows, including paralysis, ketosis, and inappetence, and the presence of roquefortine $\mathrm{C}$ in an extremely high concentration $(25 \mathrm{mg} / \mathrm{kg})$ in ensiled barley grain fed to the animals. A low toxicity of roquefortine C in sheep was demonstrated by Tüller (2005). In that study no toxic effects nor aberrant hematological, endocrinological, and enzymological parameters in blood were observed in sheep administered 10 or $50 \mathrm{mg}$ of roquefortine $\mathrm{C}$ per day $(0.13$ and $0.62 \mathrm{mg} / \mathrm{kg}$ of $\mathrm{BW}$, respectively) for a period of $20 \mathrm{~d}$. The only physiological effect that was detected was a decrease of the $\mathrm{pH}$ of rumen fluid by 0.4 unit in sheep receiving $50 \mathrm{mg}$ of roquefortine $\mathrm{C}$ per day. These observations indicate that roquefortine $\mathrm{C}$ can induce a shift in the rumen microflora composition at high concentrations. This is in agreement with a low antimicrobial activity of roquefortine $\mathrm{C}$ as reported previously (Kopp-Holtwiesche and Rehm, 1990). Assuming an average BW of lactating dairy cows of $600 \mathrm{~kg}$, the average and maximum intake of roquefortine $\mathrm{C}$ determined in the current study were 0.013 and $0.065 \mathrm{mg} / \mathrm{kg}$ of BW, respectively. These intake levels are substantially lower than the intake levels in the study by Tüller (2005). Therefore, it is unlikely that in the current study the contamination of silage with roquefortine $\mathrm{C}$ had an adverse effect on animal health or physiology. Mycophenolic acid has 
been shown to possess a low antimicrobial activity and immunosuppressive effects (Bentley, 2000). Available data indicate that the toxicity of mycophenolic acid in ruminants is low: no adverse effects on animal health and biochemical and hematological parameters in blood were detected in sheep administered $300 \mathrm{mg}$ of mycophenolic acid (5.4 mg/kg of BW) per day for a period of $44 \mathrm{~d}$ (Mohr et al., 2007). The average and maximum intakes of mycophenolic acid determined in the current study were 0.008 and $0.054 \mathrm{mg} / \mathrm{kg}$ of BW, respectively. Based on these data, it appears unlikely that in the current study the contamination of silage with mycophenolic acid had a direct adverse effect on animal health.

Little information is available about the possible chronic effects of mycotoxins and combinations of mycotoxins to cattle (CAST, 2003). One of the issues that requires more research is the effect of long-term exposure of animals to mycotoxins with immunosuppressive effects, such as DON and mycophenolic acid, which may increase their susceptibility to infectious diseases.

No data on the carry-over rates of roquefortine $\mathrm{C}$ and mycophenolic acid from feed into milk are available. However, it is likely that the transfer to milk is low because in studies with sheep a low transfer of these mycotoxins to blood plasma and body tissues was detected (Tüller, 2005; Mohr et al., 2007). Low concentrations of roquefortine $\mathrm{C}$ and mycophenolic acid have been reported in certain types of mold ripened cheeses, arising from the use of $P$. roqueforti strains in the commercial manufacture of these cheeses (Lafont et al., 1979; Ware et al., 1980). However, because of the low concentrations and low toxicity of the mycotoxins, consumption of these cheeses is not considered a relevant food safety issue (US EPA, 1997). Based on these data it is concluded that occurrence of roquefortine $\mathrm{C}$ and mycophenolic acid in silages in concentrations detected in the current study is not of significant concern with respect to the safety of dairy products for consumers.

\section{CONCLUSIONS}

Deoxynivalenoland zearalenone were identified as the mycotoxins with the highest incidence in the diet of dairy cattle in the Netherlands (81 and 46\%, respectively), and were detected in both the roughage and concentrate fraction of the diet. Deoxynivalenoland zearalenone co-occurred in $44 \%$ of the diets. High incidences of roquefortine $\mathrm{C}$ and mycophenolic acid were found in silages (23 and 17\%, respectively). The incidence of fumonisins was low (4\%) and other mycotoxins relevant to cattle, such as aflatoxin $B_{1}$, ochratoxin $A$, sterigmatocystin, and T2-toxin, were not detected in this survey. Corn silage was the most important source of mycotoxins in the diet. Intakes of the 20 mycotoxins by dairy cows determined in this study were below the EU guidance values where such are available, and therefore no acute effects on animal health are expected. However, these data are insufficient to speculate on presence of other mycotoxins, effects of multiple mycotoxin interactions, or possible chronic effects.

\section{REFERENCES}

Arnold, D. L., P. M. Scott, P. F. McGuire, J. Harwig, and E. A. Nera. 1978. Acute toxicity studies on roquefortine and PR toxin, metabolites of Penicillium roqueforti in the mouse. Food Cosmet. Toxicol. 16:369-371.

Auerbach, H., E. Oldenburg, and F. Weissbach. 1998. Incidence of Penicillium roqueforti and roquefortine $\mathrm{C}$ in silages. J. Sci. Food Agric. 76:565-572.

Bentley, R. 2000. Mycophenolic acid: A one hundred year odyssey from antibiotic to immunosuppressant. Chem. Rev. 100:38013826.

CAST (Council for Agricultural Science and Technology). 2003. Mycotoxins: Risks in plant, animal, and human systems. Task Force Report No. 139. Council for Agricultural Science and Technology, Ames, IA.

Cole, R. J., and R. H. Cox. 1981. Handbook of toxic fungal metabolites. Academic Press, New York, NY.

De Nijs, M., E. A. Sizoo, F. M. Rombouts, S. H. Notermans, and H. P. Van Egmond. 1998. Fumonisin $B_{1}$ in maize for food production imported in The Netherlands. Food Addit. Contam. 15:389392.

Driehuis, F., S. J. W. H. Oude Elferink, and P. G. Van Wikselaar. 2001. Fermentation characteristics and aerobic stability of grass silage inoculated with Lactobacillus buchneri, with or without homofermentative lactic acid bacteria. Grass Forage Sci. 56:330-343.

Driehuis, F., M. C. Spanjer, J. M. Scholten, and M. C. Te Giffel. 2008. Occurrence of mycotoxins in maize, grass and wheat silage for dairy cattle in the Netherlands. Food Addit. Contam. B 1:4150.

EFSA (European Food Safety Authority). 2004a. Opinion of the Scientific Panel on Contaminants in the Food Chain on a request from the Commission related to Aflatoxin B1 as undesirable substance in animal feed. The EFSA Journal 39:1-27.

EFSA (European Food Safety Authority). 2004b. Opinion of the Scientific Panel on Contaminants in the Food Chain on a request from the Commission related to Deoxynivalenol (DON) as undesirable substance in animal feed. The EFSA Journal $73: 1-41$.

EFSA (European Food Safety Authority). 2004c. Opinion of the Scientific Panel on Contaminants in the Food Chain on a request from the Commission related to Zearalenone as undesirable substance in animal feed. The EFSA Journal 89:1-35.

EFSA (European Food Safety Authority). 2004d. Opinion of the Scientific Panel on Contaminants in the Food Chain on a request from the Commission related to ochratoxin A (OTA) as undesirable substance in animal feed. The EFSA Journal 101:1-36.

EFSA (European Food Safety Authority). 2005. Opinion of the Scientific Panel on Contaminants in the Food Chain on a request from the Commission related to fumonisins as undesirable substances in animal feed. The EFSA Journal 235:1-32.

European Commission. 2006. Commission Recommendation of 17 August 2006 on the presence of deoxynivalenol, zearalenone, ochratoxin A, T-2 and HT-2 and fumonisins in products intended for animal feeding (2006/576/EC). Off. J. L 229:7-9.

FAO (Food and Agriculture Organization). 2001. Safety evaluation of certain mycotoxins in food. WHO Food Additives Series No. 47. FAO Food Nutr. Pap.:74 Food and Agriculture Organization, Rome, Italy. 
Gareis, M., R. C. Schothorst, A. Vidnes, C. Bergsten, B. Paulsen, C. Brera, and M. Miraglia. 2003. Collection of occurrence data of Fusarium toxins in food and assessment of dietary intake by the population of EU member states. Report of experts participating in SCOOP Task 3.2.10. http://europa.eu.int/comm/food/fs/scoop/ task3210.pdf Accessed Nov. 28, 2007.

Häggblom, P. 1990. Isolation of roquefortine C from feed grain. Appl. Environ. Microbiol. 56:2924-2926.

Hochsteiner, W., and M. Schuh. 2001. Zum Vorkommen der Fusarientoxine Desoxynivalenol und Zearalenon in österreichischen Futtermitteln im Zeitraum von 1995 bis 1999. Dtsch. Tierarztl. Wochenschr. 108:19-23.

Kopp-Holtwiesche, B., and H. J. Rehm. 1990. Antimicrobial action of roquefortine. J. Environ. Pathol. Toxicol. Oncol. 10:41-44.

Lafont, P., J. P. Debeaupuis, M. Gaillardin, and J. Payen. 1979. Production of mycophenolic acid by Penicillium roqueforti strains. Appl. Environ. Microbiol. 37:365-368.

LEI (Landbouw-Economisch Instituut). 2006. Land- en tuinbouwcijfers 2006. Landbouw-Economisch Instituut, Den Haag, the Netherlands: 95.

Mohr, A. I., I. Lorenz, B. Baum, M. Hewicker-Trautwein, M. Pfaffl, A. Dzidic, H. H. Meyer, J. Bauer, and K. Meyer. 2007. Influence of oral application of mycophenolic acid on the clinical health status of sheep. J. Vet. Med. A 54:76-81.

Pahlow, G., R. E. Muck, F. Driehuis, S. J. W. H. Oude Elferink, and S. F. Spoelstra. 2003. Microbiology of Ensiling. Pages 31-93 in Silage Science and Technology. Agronomy Monograph 42. D. R. Buxton, R. E. Muck, and J. H. Harrison, ed. American Society of Agronomy, Crop Science Society of America, and Soil Science Society of America, Madison, WI.

Reutter, M. 1999. Zearalenon und Deoxynivalenol in Getreide und Futtermitteln Schleswig-Holsteins: Untersuchungen aus den Erntejahr 1998. Pages 5-9 in Proc. 21st Mykotoxin-Workshop, Bundesinstitut für gesundheitlichen Verbraucherschutz und Veterinärmedizin, Jena, Germany.

Schneweis, I., K. Meyer, S. Hörmansdorfer, and J. Bauer. 2000. Mycophenolic acid in silage. Appl. Environ. Microbiol. 66:36393641.

Scudamore, K. A., M. T. Hetmanski, H. K. Chan, and S. Collins. 1997. Occurrence of mycotoxins in raw ingredients used for animal feeding stuffs in the United Kingdom. Food Addit. Contam. 14:157-173.

Scudamore, K. A., S. Nawaz, and M. T. Hetmanski. 1998. Mycotoxins in ingredients of animal feeding stuffs: II. Determination of mycotoxins in maize and maize products. Food Addit. Contam. 15:30-55.

Spahr, U., B. Walther, R. Sieber, J.-L. Gafner, and D. Guidon. 1999. Occurrence of mycotoxins in feeds and carry over into milk. A review. Mitt. Lebensm. Hyg. 90:575-609.

Spanjer, M. C., P. M. Rensen, and J. M. Scholten. 2008. LC-MS/ MS multi-method for mycotoxins after single extraction, with validation data for peanut, pistachio, wheat, maize, cornflakes, raisins and figs. Food Addit. Contam. 25:472-489.

Tanaka, T., S. Yamamoto, A. Hasegawa, N. Aoki, J. R. Besling, Y. Sugiura, and Y. Ueno. 1990. A survey of the natural occurrence of Fusarium mycotoxins, deoxynivalenol, nivalenol and zearalenone, in cereals harvested in the Netherlands. Mycopathologia 110:19-22.

Tüller, G. 2005. Einfluss von Roquefortine C auf Tiergesundheid und Lebensmittelqualität bei Wiederkäuern. PhD Thesis. Technische Universität München, München, Germany.

US EPA (United States Environmental Protection Agency). 1997. Penicillium roqueforti Final Risk Assessment. http://www.epa. gov/oppt/biotech/pubs/fra/fra008.htm Accessed Nov. 28, 2007.

Van Duinkerken, G., G. André, M. De Haan, C. J. Hollander, and R. L. G. Zom. 2007. Feed conversion of dairy cattle (De voederconversie van melkvee). Rapport 20. Animal Sciences Group, Lelystad, the Netherlands.

Ware, G. M., C. W. Thorpe, and A. E. Pohland. 1980. Determination of roquefortine in blue cheese and blue cheese dressing by high pressure liquid chromatography with UV and electrochemical detectors. J. Assoc. Off. Anal. Chem. 63:637-641.

Whitlow, L. W., and W. M. Hagler. 2005. Mycotoxins: A review of dairy concerns. Pages 47-58 in Proc. Mid-South Ruminant Nutrition Conference, Texas Animal Nutrition Council, Dallas, TX. http://www.txanc.org/proceedings/2005/MycoTexas.pdf Accessed October 10, 2007. 